of the fact that certain of their beliefs are regarded with suspioion by their friends and associates. When questioned bluntly concerning certain delusions which are supposed to exist, it is not uncommon for the patient to refuse to talk upon the subject. Again, I have known patients who, having been warned by legal advisers not to speak upon the topics about which they had delusions, were able for a considerable time to obey this injunction. It is nearly always possible, however, by patient and wary questioning, to get the insane individual headed toward his delusions if any exist. This is much easier to accomplish if one knows beforehand what the nature of the delusion is. The examination of a suspected case of insanity should never be hurried. In many cases one may recognize the existence of insanity at a glance, but in others many and repeated examinations are necessary either to bring out the delusions or to demonstrate the patient's sanity.

One is often asked on the witness stand if the time alleged to have been devoted to the examination of a the suspected case of insanity was sufficient. Such a question must be answered in a very general way. If certain incontestable evidences of unsound mind have. been educed then the examination, however brief, was sufficient to establish the question of insanity. If, on the other hand, the examination was negative, it is necessary to show that the patient was examined carefully upon all the subjects on which he was suspected of having entertained delusions. A single examination, with negative results, should rarely ever be relied upon. When a question has been raised, as to the mental condition of an individual, sanity is often far more difficult to establish than insanity. As was remarked before, patients are often unwilling to speak freely of their delusions. There is at present under my care a lady who was under observation in a private room in a hospital for more than 'a month before she gave any conclusive evidence of the existence of delusions. She simply seemed greatly depressed but would never give any reason for her depression. Although I had seen her nearly every day for a month I could never bring out any semblance of a delusion until one day she told me that all the people who passed the hospital shook their heads at her and showed great joy at the fact that she had been deprived of her liberty.

One should be cautious in accepting statements made by the patient as evidence of the existence of an insane delusion unless the facts of the case are well known. This is particularly true in regard to alleged ill treatment by relatives and questions involving property. Sometimes so-called delusions are simply exaggerated statements of existing conditions. Not infrequently I have been obliged to agree with the supposed lunatic in regard to the treatment received at the hands of relatives. This brief reference to some of the salient points to be noted in the examination of a case of supposed mental disease will suffice to show the care with which such examinations should be conducted. It is only by the exercise of this caution that mistakes can be avoided. By mistakes is not meant simply the commitment of sane persons to an asylum; this is sometimes, though in my opinion very rarely done, but the commitment of persons to an asylum who could have been treated as well at home.

Unfortunately, in this country there remains a great leal of the old feeling regarding the insane and asy- lums. A person who has once been committed to an asylum bears an ineffaceable stigma. Then too, in the mind of the laity such undue significance attaches to the hereditary influence of an isolated case of insanity that the fact that a member of a family has at some time been committed to an asylum constitutes almost a blot upon the escutcheon. These considerations attest the grave responsibility resting upon the physician in committing a patient to an asylum and demand a more thorough examination of the patient and his environment than is sometimes employed.

The consequences to the physician in wrongly committing patients to asylums rarely rise to the point of criminality. Such instances could be mentioned but, to the credit of the profession be it said, they are extremely rare. On the other hand, it happens very often that physicians are culpable in not making a more thorough examination of supposed cases of insanity. Most of these mistakes are known only by the asylum superintendent, although not infrequently they are recognized by the patient's friends afterward. The place where this careless and superficial work is frequently shown up is in the court room. Anyone who has had much court experience in cases of insanity must have seen a great many instances where lawyers have shown most conclusively, that the examination of the case of supposed insanity has been made in the most careless manner. Often the statements of relatives, more or less known to the physician, are taken to prove the existence of mental disease. Then it is most common to find that the physician has made no general examination of the patient and is unable to state whether or not any evidences of organic disease exist.

Great discredit has of late been cast upon expert medical testimony in regard to insanity. While in some instances the so-called expert is criminally corrupt or simply incompetent, in many and perhaps the greater number of cases, his examination has been entirely inadequate. It would be well if our medical journals would take more interest in the expert testimony given in the courts and analyze the more important cases. In this manner the profession would be placed in a position to pass judgment upon the medical testimony and the medical expert.

\section{THE PETERSON HOSPITAL AT THE CRAIG COLONY FOR EPILEPTICS.}

\section{BY WILLIAM P. SPRATLING, M.D. MEDICAL SUPERINTENDENT GRAIG COLONY.$$
\text { SONYEA, N. Y }
$$

The Peterson Hospital at the "Craig Colony for Epileptics" was designed for the care and treatment of acute medical and surgical cases only, and its capacity is from twenty to twenty-four beds. Located as it is in a colony of this kind, it is more than a hospital only, as will be pointed out.

The style of architecture is not ornate, simplicity and solidity being the chief features aimed at. It is two stories high, with an ample basement that is light, well underdrained, and in which are located the heating and hot water supplying appliances for the building, besides containing ample storage room for miscellaneous supplies. It is constructed of a superior quality of red pressed brick, with blue stone foundation walls to the water table, and trimmings of the same stone throughout. It measures from front to rear 66 feet; from side to side 120 feet; and its lines 
are so run that sunlight enters all of the rooms at some hour of the day.

The main entrance faces north and on passing into the building by this door the main hallway, 18 by 26 feet, with a projecting hallway half as large as this and running from it to the rear. is entered. The main hallway will serve the additional purpose of a public reception room.

To the right is a spacious well lighted apartment, to be occupied by the assistant medical staff as an office. Immediately in the rear of this office, and including the intervening hallway, are the living quarters for the resident medical officer.

To the left of the main entrance is the physical examination room, and opening off this a large dark room fitted with all facilities for ophthalmic work and for photographic microscopy. The physical examination room will serve the same purposes afforded by the out-door departments of a metropolitan public hospital. Examinations of all kinds may be made here and all minor injuries receive prompt attention. Adjoining this room is a small apartment in which out-door patients may be isolated and cared for, should they have a seizure while in the building.

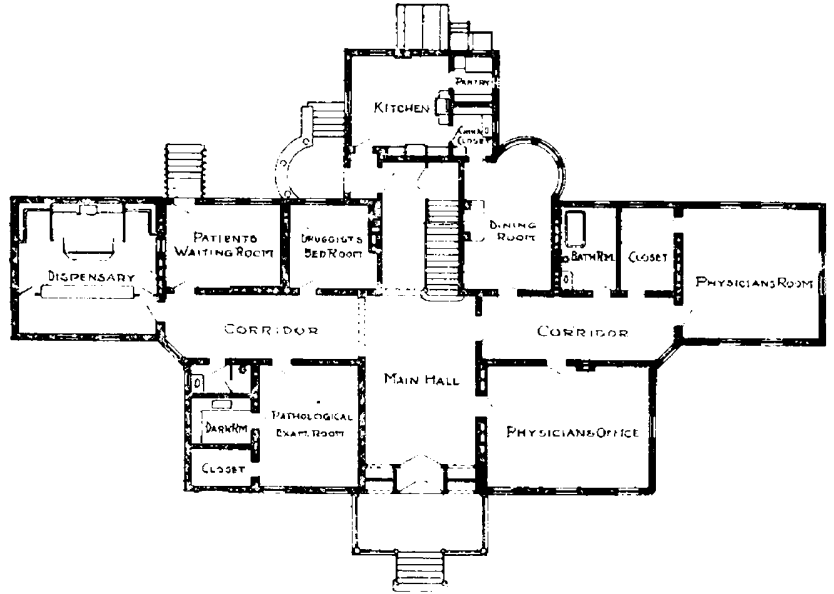

Plan of first story.

At the end of the corridor on the left is the drug room, and communicating with this. by means of a raised window, is the waiting room for persons who may come for drug supplies. All the medicine for the entire colony will be dispensed from the drug room. After a tour of inspection over the colony, the physicians will return to the drug room and enter in the prescription book all medicine and druggist's supplies to be used in their respective departments, so that this room will become the central supply station for a population that may reach 1500 or 1800 . Adjoining the waiting room is the druggist's sleeping apartment, easy of access to duty or call, day and night. The kitchen is immediately in the rear and connected with the dining room above by a dumb waiter.

The second floor is given up to patients' use, and the problem to be met was to effectually separate the two sexes in a building of this size, and without sacrifice of space.

Ascending the main stairway, a landing is made in a hallway above, twelve feet wide. Opening off from the right of this is the male department, and from the left the female, both entrances being protected by locked doors. At the end of the hallway is the operating room, a well lighted, antiseptically constructed and conveniently arranged room in all respects. It is equally accessible from the male and female wards The male and female departments, as will be noted by glancing at the second floor plan, are exact counterparts.

Lying to the north of the hallway leading to the main ward are two wards, 9 by 19 feet, in which one or two beds may be placed, as desired. A well lighted clothes room adjoins the operating room on either side. The main wards are 19 by 20 feet, are perfectly lighted and have effective ventilation. The toilet fixtures and bath are placed in separate rooms, permit. ting the free use of the bath at all times.

The convalescent rooms are cheerful, abundantly lighted, provided with open fires, and are in easy proximity to the dining room beyond. The doors leading from the convalescent rooms, on either side, to the dining room, will be kept locked, thus providing two sets of locked doors between the sexes. Safety is further assured by the fact that all patients in this building will be confined to bed except during convalescence, after which they will go out into the colony at large.

The operating room is fitted with the most approved and modern operating furniture, and is provided with an abundance of hot and cold spring water that is as pure as can be supplied by nature.

A summary of the purposes it is intended to serve

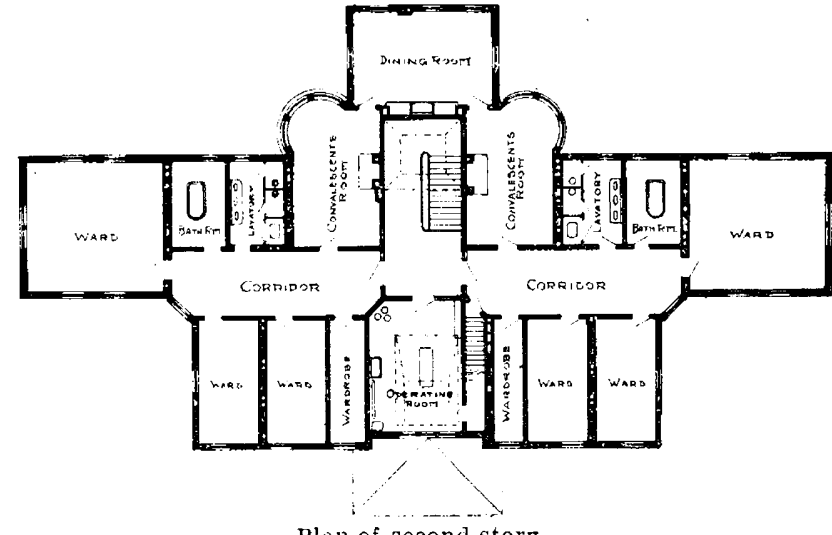

Plan of second story.

is: 1 , For the treatment of acute medical and surgical cases, requiring hospital facilities; 2 , as an accident or out-door station for the relief of dispensary cases; 3 , as a central hospital and medical supply station for a community with an ultimate public population of from 1500 to 1800 .

Dr. Frederick Peterson of New York City, who first agitated the subject of public care for epileptics in America, was honored by the Board of Managers of the Colony when this hospital was given his name.

\section{SPECIAL SANITARY INSTRUCTIONS FOR THE GUIDANCE OF TROOPS SERV. \\ ING IN TROPICAL COUNTRIES.}

BY R. S. WOODSON, M.D.

CAPT. MEDICAL DEPT. U. S. ARMY.

Having served in the extreme south during my entire service as a medical officer, viz.: Atlanta, Ga.; Pensacola, Fla.; Laredo, Texas; New Orleans, La.; Savannah, Ga.; and Tampa, Fla., and having made a special study of tropical disease, including yellow fever, it is incumbent upon the writer to publish the following special report of the existing conditions 